\title{
Public Perception of Medical Errors: Experiences and Risks Shared in Australia
}

\author{
Jeong-ah Kim ${ }^{1, *}$, Daniel Terry ${ }^{1}$, Sunny Jang $^{2}$, Hoang Nguyen ${ }^{2}$, Julia Gilbert ${ }^{1}$, Mary Cruickshank ${ }^{1}$ \\ ${ }^{1}$ School of Nursing and Healthcare Professions, Federation University Australia, Australia \\ ${ }^{2}$ Wicking Dementia Research and Education Centre, University of Tasmania, Australia
}

Received October 13, 2019; Revised November 19, 2019; Accepted November 25, 2019

Copyright $\odot 2020$ by authors, all rights reserved. Authors agree that this article remains permanently open access under the terms of the Creative Commons Attribution License 4.0 International License

\begin{abstract}
Background: Research into patient safety has largely focused on healthcare organisations bureaucratic routines, with little research available regarding the impact of patient perceptions on clinical practice. Acknowledging and openly discussing patient perceptions of medical errors may result in improved quality of healthcare. The research study aimed to gain a better understanding of the public's perception of medical errors to drive a structured approach to improve healthcare outcomes. Methods: In this study, we examined the public experiences of medical errors using an anonymous on-line survey to collect empirical data from April to December 2018. A total of 407 responses were obtained with 303 participants meeting the criteria for inclusion in the study. Results: The majority (74.9\%) of these participants identified that they had experienced a medical error during receiving healthcare in Australia and $73 \%$ of these confirmed that they were harmed as a result of these errors. Conclusion: Findings from this study indicate that many participants have experienced medical errors when accessing healthcare in Australia. These findings provide information and a deeper understanding of patient experiences and perceptions of healthcare service delivery which can be used by healthcare organisations to improve healthcare services and promote patient participation in their care.
\end{abstract}

Keywords Patient Safety, Medical Error, Public Perception, Australia

\section{Introduction}

Medical error can be defined as a mistake, or unintended act and occurrence in healthcare delivery that possibly result in patient harm (1). It is also worth mentioning that medical error is not deliberate or wilful actions that are intentionally harm the patient (2). Impacts from medical error can include further injury, overdose, under-dosage, illness, prolonged hospital stays, disability and even death, which can result from wrong medication administration, misdiagnosis of health conditions, inappropriate or inadequate treatment (3). The goal of healthcare services is to provide the best quality healthcare possible but sometimes, a healthcare provider (i.e. doctor of medicine, dentist, pharmacist, chiropractor, clinical psychologist, nurse, midwife etc.) who is regulated to practice in Australia by professional governing bodies (Australian Health Practitioner Regulation Agency; AHPRA), is often mentioned as a contributor to these errors.

A landmark study of the quality of Australian healthcare reviewed the medical records of 14,179 admissions to 28 hospitals in New South Wales and South Australia in 1995, and reported the rate of adverse medical errors was $17 \%$ of all hospital admissions. This resulted in permanent disability in $14 \%$ of patients and death in $5 \%$, while among $51 \%$ of these adverse medical errors were considered to have been preventable (4). Some estimates suggest nearly 18,000 people die every year and 50,000 people suffer a permanent injury as a consequence of medical errors, in Australia (5). Further, Berglas et al (6) found that no large studies relating to medical errors have been conducted in Australia, between 1995 and 2018. Observational studies in the U.S. have reported even higher rates. For example, $45.8 \%$ of patients experienced an adverse event that occurred during medical care, while $18 \%$ of these patients had a "serious" adverse event (7). A recent Johns Hopkins study claims more than 250,000 people in the U.S. die every year from medical errors (8), and $87 \%$ of American physicians and public believe that error reduction should be a national priority (9). Similarly, Donchin et al (10) found health professionals made 1.7 errors per patient per day at a university hospital in Israel. Canadian studies that used teaching hospital chart review over a 1- year period have found medical error rates of $7.5 \%$ and $12.7 \%$, with rates of preventable events being 
$2.8 \%$ and $4.8 \%$ in the two studies respectively $(11,12)$. It is noted that the rate of medical errors in these studies broadly ranged from $7.5 \%$ to $45.8 \%$. Furthermore, recent studies show that $45 \%$ of every dollar spent in the US is related to medical mistakes (13). Another source states the cost associated with errors was over $\$ 7$ billion dollars in 2008 and over, \$3.5 billion dollars annually is used in acute healthcare in U.S. due to adverse drug events (14).

Woolf, Kuzel, Dovey, \& Phillips (15) in their systematic review reported that medical errors often result from a chain of events. These variables in medical errors are often difficult to measure and are impacted by the varied definitions given and inadequate reporting of the same. In a study by Jha et al (16), the majority of researchers focused on investigating health care professionals' opinions or analyzing medical error incident reports; however, often the patient's own experience and perceptions of medical errors were not captured.

In consideration of the limited systematic collection and associating medical error data there is significant level of under-reporting, lack of quality of information within incident reporting, and excludes consumer's information in the reporting system (17). As such, it remains impossible to measure accurately medical mistakes that can cause serious harm or death in Australia.

Overall, research has been largely unsuccessful and limited in addressing consumers' perception of medical errors despite consumers having an increased participatory role in health care in Australian modern society (18). This lack of research impacts how quality of care is enacted for consumers through quality improvement activities and for health care professionals giving care at the grassroots level. Given the impact of medical errors and limited Australian research to date, this research seeks to provide insights concerning patient perceptions and experiences of medical errors for healthcare providers and policy makers to make improvements in care for consumers.

\section{Method}

In order to provide insights concerning perceptions and experiences of medical errors, a cross sectional design was used to explore and understand this issue through an anonymous on-line survey of the Australian population from April to December 2018.

\subsection{Aims and Objectives}

The aim of this preliminary study is to gain a better understanding of the public's experiences and perceptions of medical errors to drive a structured approach to improve healthcare outcomes.

\subsection{Participant Recruitment}

A Facebook survey was used as a participant recruitment tool. The project created a Facebook page posting recruitment advertisements with comprehensive research information. One researcher who has successfully conducted international social media research on user behaviours designed the Facebook page for recruiting participants (19), abiding by ethical procedures aligned with the National Statement on Ethical Conduct in Human Research (2017).

The recruitment advertisement on the Facebook page invited those who access Facebook who self-identified as target participants. Inclusion criteria included Australian Permanent Residents/Citizens aged 18 years or over who understand English; who have access to or received medical services. In addition, the advertisement displayed the purpose and aim of the research (e.g. image files), contact details for questions and discussion about the research, and also sought information in relation to medical errors from those who completed the survey voluntarily.

\subsection{Data Collection}

Each participant was invited to complete a 10 minute online questionnaire to explore their experience and perceptions of medical errors. The questionnaire survey was conducted through an online survey portal (Lime Survey). Data collected within the 'Public Perception of Medical Error Survey' included demographic information and key information related to their experience's and perception with details surrounding the medical error. This research replicated and expanded on the population based study modelled by Non-partisan and Objective Research Organization (NORC) by using a modified version (i.e. Australian wording) of the NORC survey for the Australian context (20).

\subsection{Analysis}

SPSS version 23 statistic software package used to perform statistical data analyses. The analysis included frequencies of discrete variables and cross-tabulation of variables. Demographics of participants, types and places of medical error experience and public perceived responsibility of medical errors were summarized using descriptive statistics. Differences in experiences with medical errors, reporting the errors and the perception of health system improvement rates between age and education were tested with Fisher's exact tests (chi-squared tests; $\chi^{2}$ ). Statistical significance was a value of $\mathrm{P} \leq 0.05$. Any qualitative data provided was thematically analyzed to identify key themes associated with medical errors that were discussed or disclosed by participants.

\subsection{Ethics}

This study was approved by Federation University Ethics Committee (Project: 18-085). Questionnaires, with 
a Plain Language Information Sheet explaining the study purpose and data confidentiality and encouraging participants' voluntary participation, were posted to the Facebook site that agreed to participate in the study. The anonymity of participants was clearly explained and assured.

\section{Results}

\subsection{Characteristics of Subjects}

Table 1. Demographic characteristics of participants

\begin{tabular}{|c|c|c|}
\hline Characteristics & $\begin{array}{c}\text { Number } \\
(\mathrm{n}=303)\end{array}$ & $\begin{array}{c}\text { Percentage } \\
(\%)\end{array}$ \\
\hline Gender & 270 & \\
Woman & 28 & 89.1 \\
Man & 5 & 9.2 \\
Other & 30 & 1.7 \\
\hline Age & 30 & 9.9 \\
-30 & 49 & 9.9 \\
$31-40$ & 92 & 16.2 \\
$41-50$ & 102 & 30.4 \\
51-60 & & 33.7 \\
61- & 4 & \\
Education & 70 & 1.3 \\
Primary & 206 & 23.1 \\
Secondary & 23 & 68.0 \\
Tertiary & & 7.6 \\
Other & 11 & \\
Region & 67 & 3.6 \\
ACT & 74 & 22.1 \\
NSW & 65 & 24.4 \\
VIC & 27 & 21.5 \\
QLD & 38 & 8.9 \\
SA & 19 & 12.5 \\
WA & 2 & 6.3 \\
Tas & & 0.7 \\
NT & & \\
\hline
\end{tabular}

*ACT(Australian capital territory), NSW (New South Wales), VIC(Victoria), QLD(Queensland), SA(South Australia), WA(Western Australia), Tas(Tasmania), NT(Northern Territory)
A total of 407 participants completed the survey, while 303 (74.4\%) provided eligible data for analysis after the removal of participants who were not Australian citizens or permanent residents and who initiated but did not complete the survey in full. Their data were excluded for ethical reasons.

Among the participants in the sample, the majority were women $(89.1 \%, n=270)$, and the overall mean age of all respondents was $53.6(\mathrm{SD}=14.624)$ with an age range from 21 to 86 years. In terms of education level, 68\% (n= 206) had obtained a tertiary education, followed by those with secondary education $(23.1 \%, n=70)$ while $1.3 \%(n=4)$ had up to primary education. The participants were predominantly resident in Victoria $(24.4 \%, \mathrm{n}=74)$, New South Wales (22.1\%, $\mathrm{n}=67)$ and Queensland $(21.5 \%$, $\mathrm{n}=65$ ) (See table 1), and all participants understood plain English. Demographic differences within groups based on sex, age, education level and region, were tested with $\chi^{2}$ tests with no significant difference reported.

\subsection{Experience and Reporting of Medical Error}

Results related to experiences of medical errors, including those which involved the respondents personally, and whether these resulted in sustained physical or emotional harm are presented in Table 2. Overall, $74.9 \%(n=227)$ of all respondents reported they had experienced a medical error while receiving care in an Australian health setting, and $73.5 \%(n=220)$ indicated that the error had resulted in the harm of the participant. A high proportion of participants who reported a medical error were over 50 years of age $(63.5 \%, n=144)$ and had achieved a tertiary education $(70 \%, \mathrm{n}=159)$. However, there was no significant relationship between the demographics of age or education and exposure to medical error or harm.

Table 2. Relationship between participants' individual characteristics (age \& education) and their experience of medical error using chi-squared tests

\begin{tabular}{|c|c|c|c|c|c|c|}
\hline & \multicolumn{3}{|c|}{ Participant has experienced medical error } & \multicolumn{3}{|c|}{$\begin{array}{l}\text { Participant has been harmed, either physically or } \\
\text { emotionally when they, received medical care }\end{array}$} \\
\hline & $\begin{array}{l}\text { Participant } \\
\text { numbers }\end{array}$ & $\begin{array}{l}\text { n (\% within } \\
\text { age group) }\end{array}$ & $\begin{array}{l}\mathrm{n}(\% \text { within } \\
\text { total sample) }\end{array}$ & $\begin{array}{c}\text { Participant } \\
\text { numbers }\end{array}$ & $\begin{array}{l}\mathrm{n} \text { (\% within } \\
\text { age group) }\end{array}$ & $\begin{array}{l}\mathrm{n} \text { (\% within } \\
\text { total sample) }\end{array}$ \\
\hline Age (years) & & & & & & \\
\hline-30 & 25 & 83.3 & 11.0 & 23 & 76.7 & 10.5 \\
\hline $31-40$ & 20 & 66.7 & 8.8 & 19 & 63.4 & 8.6 \\
\hline $41-50$ & 38 & 77.6 & 16.7 & 38 & 77.6 & 17.3 \\
\hline $51-60$ & 71 & 77.2 & 31.3 & 65 & 70.7 & 29.5 \\
\hline 61- & 73 & 71.6 & 32.2 & 75 & 73.5 & 34.1 \\
\hline Total & 227 & 74.9 & 100 & 220 & 73.5 & 100 \\
\hline$P$ value & \multicolumn{3}{|c|}{$\mathrm{P}=0.247$} & \multicolumn{3}{|c|}{$\mathrm{P}=0.446$} \\
\hline Education & & & & & & \\
\hline Primary & 4 & 100 & 1.8 & 4 & 100 & 1.8 \\
\hline Secondary & 49 & 70 & 21.6 & 48 & 68.6 & 21.8 \\
\hline Tertiary & 159 & 77.2 & 70.0 & 153 & 74.3 & 69.5 \\
\hline Other & 15 & 65.2 & 6.6 & 15 & 65.2 & 6.8 \\
\hline Total & 227 & 74.9 & 100 & 220 & 72.6 & 100 \\
\hline P value & \multicolumn{3}{|c|}{$\mathrm{P}=0.346$} & \multicolumn{3}{|c|}{$\mathrm{P}=0.502$} \\
\hline
\end{tabular}


It should be also noted medial errors were not reported as often as they could have been (See Table 3). In this case, only $49.3 \% \quad(n=112)$ participants out of 227 participants who had experienced a medical error reported medical errors received during their care. When the relationship between reporting the error, age and education were analysed, the reporting of the event was not related to age and educational group. As such, $67.9 \%$ $(\mathrm{n}=76)$ of the tertiary educated group reported the error, whilst only $32.1 \%(n=36)$ of the other educational groups including primary, secondary and 'other' reported the error. Rates of reporting did not differ significantly by age and education group. As a result, approximately 50.6\% $(n=115)$ of the respondents did not report the error or raise concerns despite having received an adverse event associated with their care. It is assumed that public concerns and/or suggestions to improve patient safety may seem disregarded.

Table 3. Relationship between participants' individual characteristics (age $\&$ education) and reporting medical error using chi-squared test

\begin{tabular}{|c|c|c|}
\hline & $\begin{array}{c}\text { Participant has } \\
\text { experienced medical error } \\
\text { reported the event } \\
(\mathrm{n}=227)\end{array}$ & $\mathrm{p}$-value \\
\hline Age & $11(9.8 \%)$ & \\
-30 & $8(7.1 \%)$ & \\
$31-40$ & $23(20.5 \%)$ & $\mathrm{p}=0.204$ \\
$41-50$ & $26(23.2 \%)$ & \\
$51-60$ & $44(39.3 \%)$ & \\
$61-$ & $112(49.3 \%)$ & \\
Total & $3(2.7 \%)$ & \\
Education & $20(17.9 \%)$ & $\mathrm{p}=0.024$ \\
Primary & $76(67.9 \%)$ & \\
Secondary & $13(11.6 \%)$ & \\
Tertiary & $112(49.3 \%)$ & \\
Other & & \\
Total & &
\end{tabular}

\subsection{Type and Place of Medical Error}

To examine the types of medical errors occurring in health care settings, participants who had experienced a medical error were asked about the nature of the error that had occurred. Table 4 shows that the top three types of medical errors experienced were: misdiagnosis (59\%, $\mathrm{n}=134)$, treated disrespectfully $(55.5 \%, \mathrm{n}=126)$, and mistake made during procedure $(44 \%, n=100)$. As such, this study highlighted that among many participants $(84.5 \%, n=234)$ who have experienced medical errors had reported medical errors related to diagnostic and treatment issues that arose during the care. Further, as shown in Table 4, among participants who had experienced medical errors, medication/treatment errors by a nurse were reported as an error type by a relatively small number of participants $(15.4 \%, \mathrm{n}=35)$.

From the data reported by participants who had experienced, or had someone in their care experience an error, it was found that the majority of medical errors took place in a doctor's office or acute hospital settings. Specifically, $52.4 \%(\mathrm{n}=119)$ occurred in the hospital, while $48.9 \%(n=111)$ of medical errors occurred in a doctor's office, and $27.3 \%(n=62)$ in the Emergency Room (ER). Comparatively few medical errors were reported in nursing homes, pharmacies and dental office settings (1.3-2.2\%).

Table 4. Participant responses to a list of types of medical errors

\begin{tabular}{|l|c|}
\hline \multicolumn{1}{|c|}{ Type } & $\begin{array}{c}\text { Number (\%) } \\
(\mathrm{n}=277)\end{array}$ \\
\hline Medical problem was Misdiagnosis & $134(59 \%)$ \\
\hline Treated disrespectfully & $126(55.5 \%)$ \\
\hline $\begin{array}{l}\text { Mistake made during a test, surgery or } \\
\text { treatment }\end{array}$ & $100(44 \%)$ \\
\hline $\begin{array}{l}\text { Received wrong medication/treatment from a } \\
\text { Doctor }\end{array}$ & $63(27.7 \%)$ \\
\hline Received a diagnosis that did not make sense & $59(26 \%)$ \\
\hline $\begin{array}{l}\text { Got an infection after a hospitalisation or } \\
\text { treatment }\end{array}$ & $49(21.6 \%)$ \\
\hline Received treatment that was not needed & $44(19.4 \%)$ \\
\hline Given wrong instructions about follow-up care & $41(18 \%)$ \\
\hline Test results were lost, delayed or not shared & $36(15.9 \%)$ \\
\hline $\begin{array}{l}\text { Received wrong medication/treatment from a } \\
\text { Nurse }\end{array}$ & 35 15.4\%) \\
\hline $\begin{array}{l}\text { Were administered the wrong medication } \\
\text { dosage }\end{array}$ & $28(12.3 \%)$ \\
\hline $\begin{array}{l}\text { Were given instructions from different health } \\
\text { care providers }\end{array}$ & $9(3.9 \%)$ \\
\hline Fell down or out of bed & $9(3.9 \%)$ \\
\hline Patient misunderstood the care plan & $5(2.2 \%)$ \\
\hline Received wrong medication from a Pharmacy & $4(1.7 \%)$ \\
\hline $\begin{array}{l}\text { Accidently took too much /or wrong } \\
\text { medication }\end{array}$ & $3(1.3 \%)$ \\
\hline Got a bed sore & $3(1.3 \%)$ \\
\hline Received wrong medication from a Midwife & $2(0.9 \%)$ \\
\hline
\end{tabular}

The results depicted in Table 5, indicate that the large majority of respondents of $(82.8 \%, n=251)$ feel that health care professionals have the major responsibility for ensuring a patient's safety. Although we did not ascertain the reasons for this response, participants were less likely to believe that hospital leaders had the responsibility of addressing the problem of medical errors than those staff directly involved in the care.

Table 5. Participant responses to who has a responsibility for ensuring a patient safety

\begin{tabular}{|l|c|}
\hline \multicolumn{1}{|c|}{ Responsibility } & $\begin{array}{c}\text { Number (\%) } \\
(\mathrm{n}=303)\end{array}$ \\
\hline $\begin{array}{l}\text { Doctors, nurses and other health care } \\
\text { providers }\end{array}$ & $251(82.8 \%)$ \\
\hline Patient themselves & $179(59.1 \%)$ \\
\hline Family members and caregivers of patients & $163(53.8 \%)$ \\
\hline Hospital leaders and administrators & $155(51.5 \%)$ \\
\hline Government & $120(39.6 \%)$ \\
\hline Health insurance Company & $41(13.5 \%)$ \\
\hline Consumer groups & $38(12.5)$ \\
\hline
\end{tabular}


Table 6. Participants' perception of current health care status and experiencing medical errors using chi-squared tests

\begin{tabular}{|c|c|c|c|c|c|c|}
\hline \multirow{2}{*}{ Medical error } & \multicolumn{3}{|c|}{ Over the past five years, do you think that patient safety in health care } & \multirow{2}{*}{ Total (\%) } & \multirow{2}{*}{$\mathrm{p}$ value } \\
\cline { 2 - 5 } & $\begin{array}{c}\text { Better } \\
\mathrm{n}(\%)\end{array}$ & $\begin{array}{c}\text { Same } \\
\mathrm{n}(\%)\end{array}$ & $\begin{array}{c}\text { Worse } \\
\mathrm{n}(\%)\end{array}$ & $\begin{array}{c}\text { Other } \\
\mathrm{n}(\%)\end{array}$ & & \\
\hline experienced & $19(8.4)$ & $41(18.1)$ & $88(38.8)$ & $79(34.8)$ & $227(74.9)$ & \\
not experienced & $4(6.3)$ & $5(7.8)$ & $22(34.4)$ & $64(21.1)$ & $64(21.1)$ & $\mathrm{p}=0.000$ \\
didn't wish to respond & $0(0)$ & $0(0)$ & $0(0)$ & $12(4)$ & $12(4)$ & \\
\hline Total & $23(7.6)$ & $46(15.2)$ & $110(36.3)$ & $124(40.8)$ & $303(100)$ & \\
\hline
\end{tabular}

\subsection{Perception of Current Health Care Service}

As shown in Table 6, approximately half of the participants $(51.5 \%, \mathrm{n}=156)$ who responded to the questionnaire thought that patient safety in healthcare delivery had not improved and only slightly more than a third $(36.3 \%, \mathrm{n}=110)$ felt that patient care safety had become worse. There is a significant difference between groups of different medical error experiences $(p=0.000)$ while no significant difference in perception was found between education and age group.

\section{Discussion}

Overall, the findings indicated that the majority of respondents were from the three most populace states in Australia, which is unsurprising, and the majority of the participants were women and over the age of 50 years. Again, this was anticipated given the demographic who are more likely to use Facebook as a medium of connection and communication (21).

Given the survey was a modified version of the survey from the NORC study (20), it was noted that the findings were dissimilar in terms of percentage of individuals who experienced the error themselves. As such, the results (74.9\%) were found to be much higher than those found in the US where $41.0 \%$ of respondents reported involvement with a medical error, either personally or second-hand (20), and in a Canadian study, where $37.0 \%$ of respondents reported ever having experienced a medical error (22). This finding may suggest higher actual numbers of errors in Australia, or given the social media recruitment method of the participants who were self-selected to participate in the study rather than the random nature of the participant selection in the other studies (23).

In many cases, the errors were mostly related to misdiagnosis, medical mistakes being made during a procedure and treatment, and also being treated disrespectfully. This is consistent with the findings from the NORC study and from the study conducted by Burroughs et al (24), which also highlighted that patients were concerned regarding misdiagnoses, physician errors, wrong test or procedure, and problems with medical equipment (20). Similarly, in another Australian study by Weingart et al (5), “ a failure of action such as a missed diagnosis, a delayed evaluation, or a failure to prescribe needed drug treatment" was shown to often outnumber an erroneous action such as administering the wrong drug by two to one ( $5 \mathrm{p} 776)$. The findings of this study are also consistent with the findings of Woolf et al (15) who found that, among 83 medical errors, $83 \%$ were treatment related, and $15 \%$ were errors in diagnosis, and $17 \%$ were errors in communication. This suggests that there is a need for greater education and support to improve accuracy in terms of treatment and diagnosis, and emphasis be placed on better communication between healthcare professionals and the patient.

Overall, it was noted that $49.3 \%$ of the Australian participants in the current study had reported an actual medical error they experienced during the care which was and slightly higher than the findings from the NORC study, which showed that $45.0 \%$ of US participants had reported a medical error (20). This finding suggests that consumers either do not know where to report, how to report, or are fearful to report a medical error (25). Alternatively, this may be due to long term care implications for reporting the error $(26,27)$. Although the motivations to report an error are different among healthcare professionals, it remains problematic among both patients and health professionals $(9,28)$. This growing body of evidence demonstrates that underreporting by both healthcare consumers and healthcare professionals may be a critical factor in assessing the component of healthcare quality and patient safety.

In addition, it has been found that when an error has occurred, although patients do not always report the error, nor seek malpractice lawsuits, they do desire some element of formal recognition and apology of the error (29, 30). Further, when a medical error occurs and a patient's concerns are not addressed, there is a tendency that they are less likely to show up for future care needs, not to adhere medical advice, and seek professional misconduct claims (31).

It is also interesting to note that quality and safety in healthcare can be measured and defined as consumer's satisfaction level (32), and measuring patient's experience is a critical step in understanding and improving the quality of care. This study has demonstrated that participant's experience correlates with outcome of level perception of healthcare status. For example more than 
half of the participant who have experienced and have been impacted by a medical error reported they were dissatisfied with the standard of healthcare when asked about the current level of patient safety. This quite palpable view provides an insight into the system-level problems they have perceived during their care.

Lastly, underreporting of, and failure to report errors and near misses from both the healthcare professionals and the patients hinders efforts to prevent future errors and circumvent an organisation's and health professional's obligation to inform and disclose to patients about the error (33).

\subsection{Limitations of the Project}

Although the results of this study suggest some general relationships between public perceptions and characteristics of medical errors, it is possible that the findings are sometimes inconsistent compared with other studies. These inconsistencies may be related to response bias, differences in data collection methods and timing of surveys, and differences in survey instruments. A consequence of using Facebook as a recruitment method is that recruitment was voluntary and resulted in self-selected participants. This may lead to over representing individuals who have strong perceptions about medical errors (23).

\section{Conclusions}

This cross sectional study is the first study that explores medical errors on the national level to assess and understand health care consumer's current medical error experiences and perceptions in Australia using social media research method. We found several areas of concern to health professionals that may need to be addressed to improve health care services and prevent medical errors and harm to the public.

Our survey confirms that many in the Australian population have experienced medical errors and harm and these experiences are underreported or not reported. Australian patients voiced low satisfaction with health care services, demonstrated a poor recognition of organisational responsibility for medical errors and many reported that health care status in Australia is not improving. The findings of this study show the need to improve our quality of patient safety and the accuracy of event reporting. Published research (34) found that more than $70 \%$ of the adverse events were believed to be preventable. In order to ensure patient safety and to support health professionals and health care settings, this issue could be achieved through successful strategies and preventive measures.

On reflection of the findings of this study, the recommendations for addressing the issues of a high prevalence of medical errors and for reducing its risks would be professional education of quality and safety of patientcare that illustrates enhanced provision of safety practice, effective and appropriate communication between health professionals and patient about their concerns, and a better monitoring system for detecting adverse events.

Additionally, patient empowerment that including components of educational and motivation tools, and role modelling programs aimed at encouraging consumers to take an active role in decision making regarding their care may be a pivotal step.

This study serves key functions to assist health professionals to mitigate or prevent future adverse medical events and also help patient's awareness of the care received and avoid unnecessary harm in their care. Despite the limitation of the study, these findings have provided a useful and empirical data source for relevant health professionals and decision makers to understand and assess the medical error issues in Australia.

\section{Competing Interests}

The authors declares that they have no competing interests.

\section{REFERENCES}

[1] Flack M, Reed T, Crowley J, Gardner S. Advances in Patient Safety: Identifying, Understanding, and Communicating Medical Device Use Errors: Observations from an FDA Pilot Program. In: Henriksen K, Battles JB, Marks ES, Lewin DI, editors. Advances in Patient Safety: From Research to Implementation (Volume 3: Implementation Issues). Rockville (MD): Agency for Healthcare Research and Quality (US); 2005.

[2] James JT. A new, evidence-based estimate of patient harms associated with hospital care. Journal of patient safety. 2013;9(3):122-8.

[3] Burroughs TE, Waterman AD, Gallagher TH, Waterman B, Jeffe DB, Dunagan WC, et al. Patients' concerns about medical errors during hospitalization. Joint Commission journal on quality and patient safety. 2007; 33(1):5-14.

[4] Wilson RM, Runciman WB, Gibberd RW, Harrison BT, Newby L, Hamilton JD. The Quality in Australian Health Care Study. The Medical journal of Australia. 1995; 163(9):458-71.

[5] Weingart SN, Mc LWR, Gibberd RW, Harrison B. Epidemiology of medical error. The Western journal of medicine. 2000; 172(6):390-3.

[6] Berglas NF, Battistelli MF, Nicholson WK, Sobota M, Urman RD, Roberts SCM. The effect of facility characteristics on patient safety, patient experience, and service availability for procedures in 
non-hospital-affiliated outpatient settings: A systematic review. PloS one. 2018; 13(1): e0190975.

[7] Andrews LB, Stocking C, Krizek T, Gottlieb L, Krizek C, Vargish $\mathrm{T}$, et al. An alternative strategy for studying adverse events in medical care. Lancet (London, England). 1997; 349(9048):309-13.

[8] Medicine JH. Study Suggests Medical Errors Now Third Leading Cause of Death in the U.S. 2016 [Available from: https://www.hopkinsmedicine.org/news/media/releases/stu dy_suggests_medical_errors_now_third_leading_cause_of _death_in_the_us.

[9] Robinson AR, Hohmann KB, Rifkin JI, Topp D, Gilroy CM, Pickard JA, et al. Physician and public opinions on quality of health care and the problem of medical errors. Archives of internal medicine. 2002; 162(19):2186-90.

[10] Donchin Y, Gopher D, Olin M, Badihi Y, Biesky M, Sprung CL, et al. A look into the nature and causes of human errors in the intensive care unit. Critical care medicine. 1995; 23(2):294-300.

[11] Baker GR, Norton PG, Flintoft V, Blais R, Brown A, Cox J, et al. The Canadian Adverse Events Study: the incidence of adverse events among hospital patients in Canada. CMAJ: Canadian Medical Association journal = journal de l'Association medicale canadienne. 2004; 170(11): 1678-86.

[12] Forster AJ, Asmis TR, Clark HD, Al Saied G, Code CC, Caughey SC, et al. Ottawa Hospital Patient Safety Study: incidence and timing of adverse events in patients admitted to a Canadian teaching hospital. CMAJ: Canadian Medical Association journal = journal de l'Association medicale canadienne. 2004; 170(8): 1235-40.

[13] Andel C, Davidow SL, Hollander M, Moreno DA. The economics of health care quality and medical errors. Journal of health care finance. 2012; 39(1): 39-50.

[14] Pham JC, Aswani MS, Rosen M, Lee H, Huddle M, Weeks $\mathrm{K}$, et al. Reducing medical errors and adverse events. Annual review of medicine. 2012; 63: 447-63.

[15] Woolf SH, Kuzel AJ, Dovey SM, Phillips RL, Jr. A string of mistakes: the importance of cascade analysis in describing, counting, and preventing medical errors. Annals of family medicine. 2004; 2(4): 317-26.

[16] Jha AK, Prasopa-Plaizier N, Larizgoitia I, Bates DW. Patient safety research: an overview of the global evidence. Quality \& safety in health care. 2010; 19(1):42-7.

[17] Walton M, Smith-Merry J, Harrison R, Manias E, Iedema R, Kelly P. Using patients' experiences of adverse events to improve health service delivery and practice: protocol of a data linkage study of Australian adults age 45 and above. BMJ open. 2014; 4(10): e006599.

[18] Care ACfSaQiH. Open disclosure standard. 2008.

[19] Amon KL, Paxton K, Klineberg E, Riley L, Hawke C, Steinbeck K. Insights into Facebook Pages: an early adolescent health research study page targeted at parents. International journal of adolescent medicine and health. 2016; 28(1): 69-77.

[20] Institute NatUoCaINLL. Americans' experiences with medical errors and views on patient safety 2017 [Available from: http://www.ihi.org/about/news/Documents/IHI_NPS
F_NORC_Patient_Safety_Survey_2017_Final_Report.pdf.

[21] Lee JL, Choudhry NK, Wu AW, Matlin OS, Brennan TA, Shrank WH. Patient Use of Email, Facebook, and Physician Websites to Communicate with Physicians: A National Online Survey of Retail Pharmacy Users. Journal of general internal medicine. 2016; 31(1):45-51.

[22] Northcott H, Vanderheyden L, Northcott J, Adair C, McBrien-Morrison C, Norton P, et al. Perceptions of preventable medical errors in Alberta, Canada. International journal for quality in health care: journal of the International Society for Quality in Health Care. 2008; 20(2): 115-22.

[23] Wilson RE, Gosling SD, Graham LT. A Review of Facebook Research in the Social Sciences. Perspectives on psychological science: a journal of the Association for Psychological Science. 2012; 7(3): 203-20.

[24] Burroughs TE, Waterman AD, Gallagher TH, Waterman B, Adams D, Jeffe DB, et al. Patient concerns about medical errors in emergency departments. Academic emergency medicine: official journal of the Society for Academic Emergency Medicine. 2005; 12(1): 57-64.

[25] Evans SM, Berry JG, Smith BJ, Esterman AJ. Anonymity or transparency in reporting of medical error: a community-based survey in South Australia. The Medical journal of Australia. 2004; 180(11): 577-80.

[26] Doherty C, Stavropoulou C. Patients' willingness and ability to participate actively in the reduction of clinical errors: a systematic literature review. Social science \& medicine (1982). 2012; 75(2): 257-63.

[27] Hor SY, Godbold N, Collier A, Iedema R. Finding the patient in patient safety. Health (London, England: 1997). 2013; 17(6): 567-83.

[28] Poorolajal J, Rezaie S, Aghighi N. Barriers to Medical Error Reporting. International journal of preventive medicine. 2015; 6: 97.

[29] Gallagher TH, Waterman AD, Ebers AG, Fraser VJ, Levinson W. Patients' and physicians' attitudes regarding the disclosure of medical errors. Jama. 2003; 289(8): 1001-7.

[30] Kalra J, Kalra N, Baniak N. Medical error, disclosure and patient safety: a global view of quality care. Clinical biochemistry. 2013; 46(13-14): 1161-9.

[31] Schwappach DL, Koeck CM. What makes an error unacceptable? A factorial survey on the disclosure of medical errors. International journal for quality in health care: journal of the International Society for Quality in Health Care. 2004; 16(4): 317-26.

[32] Braunsberger K, Gates RH. Patient/enrollee satisfaction with healthcare and health plan. 2002; 19(7):575-90.

[33] Organization WH. Patient Safety: Making health care safer 2017 [Available from: https://apps.who.int/iris/handle/106 65/255507.

[34] Institute of Medicine Committee on Quality of Health Care in A. To Err is Human: Building a Safer Health System In: Kohn LT, Corrigan JM, Donaldson MS, editors. Washington (DC): National Academies Press (US) Copyright 2000 by the National Academy of Sciences. All rights reserved.; 2000. 